AUTONOMOUS MOBILE ROBOT TECHNOLOGY FOR SUPPLYING ASSEMBLY LINES IN THE AUTOMOTIVE INDUSTRY

Martin Čech; Pavel Wicher; Radim Lenort; Tomáš Malčic; Jiř́i David; David Holman; David Staš; Jiř́ Záruba

doi:10.22306/al.v7i2.164

Received: 03 Apr. 2020

Accepted: 06 June 2020

\title{
AUTONOMOUS MOBILE ROBOT TECHNOLOGY FOR SUPPLYING ASSEMBLY LINES IN THE AUTOMOTIVE INDUSTRY
}

\author{
Martin Čech \\ ŠKODA AUTO University, Na Karmeli 1457, 29301 Mladá Boleslav, Czech Republic, EU, martin.cech@ savs.cz \\ (corresponding author) \\ Pavel Wicher \\ ŠKODA AUTO University, Na Karmeli 1457, 29301 Mladá Boleslav, Czech Republic, EU, pavel.wicher@ savs.cz \\ Radim Lenort \\ ŠKODA AUTO University, Na Karmeli 1457, 29301 Mladá Boleslav, Czech Republic, EU, radim.lenort@savs.cz \\ Tomáš Malčic \\ ŠKODA AUTO University, Na Karmeli 1457, 29301 Mladá Boleslav, Czech Republic, EU, tomas.malcic@ savs.cz \\ Jiř́i David \\ ŠKODA AUTO University, Na Karmeli 1457, 29301 Mladá Boleslav, Czech Republic, EU, jiri.david@ savs.cz \\ David Holman \\ ŠKODA AUTO University, Na Karmeli 1457, 29301 Mladá Boleslav, Czech Republic, EU, david.holman@savs.cz \\ David Staš \\ ŠKODA AUTO University, Na Karmeli 1457, 29301 Mladá Boleslav, Czech Republic, EU, david.stas@ savs.cz \\ Jiří Záruba \\ ŠKODA AUTO a.s., tř. Václava Klementa 869, 29301 Mladá Boleslav, Czech Republic, EU, \\ jiri.zaruba@skoda-auto.cz
}

Keywords: autonomous mobile robot, automated guided vehicle, assembly line supply, automotive industry, material handling

Abstract: The ever-increasing customization and differentiation of the product portfolio and the shorter life cycle of products and technologies in the automotive industry lead to the development of flexible and convertible manufacturing and logistics technologies and systems at all stages of car production. In the field of supplying assembly lines in the automotive industry, such technologies are based on Autonomous Mobile Robots (AMRs). The aim of this paper is to create a comprehensive knowledge base for design, selection and implementation of AMR technology in the form of unit load carriers for supplying assembly line in the automotive industry. The outputs of the article are based on a case study aimed at assessing the feasibility of introducing AMR technology for supplying car assembly line parts with irregular consumption. The article presents a general procedure for feasibility study of the project of AMR assembly line supply and a comprehensive set of recommendations divided into five key categories: Technology, Management, Economics, Capacity, and Vendors.

\section{Introduction}

The trend in the current automotive industry is the increasing customization and differentiation of the product portfolio as well as the ever-shorter life cycle of products and technologies. This is a consequence of growing customer demands in a globalized and highly competitive automotive market. It can be assumed that this trend will continue through the implementation of alternative concepts of car use, new materials and technologies, changes in consumer behaviour and further individualization and personalization of cars. For this reason, it is necessary to fundamentally change the principles and technologies of production and logistics systems used by car manufacturers. It is necessary to change classical systems based on the principles of stable and mass production. For that purpose, flexible and convertible production and logistics systems are being developed at all stages of car production.

At present, automated logistics systems based on Automated Guided Vehicle (AGV) technology are used in automotive assembly. They help car manufacturers to increase the efficiency and quality of logistics processes. However, the traditional AGVs are particularly popular for the regular and stable loading of assembly lines, as they are generally based on a limited number of pre-defined paths. This would make their use for irregularly loaded parts highly inefficient (low degree of utilization considering the purchase price of AGVs).

Recently, however, AGVs have seen rapid technological development. AGVs are becoming more sophisticated, flexible and cheaper. Autonomous Mobile Robots (AMRs) are now considered the highest AGV level. Their high degree of autonomy does not require the creation of pre-defined paths and AMRs can also be 
deployed to supply assembly lines with irregularly loaded parts, the number of which is constantly increasing due to customization and differentiation of cars.

Unfortunately, a systematic literature review has shown that there is still no comprehensive knowledge base (a comprehensive set of recommendations) to design, select and implement AMR technology for supplying an assembly line in the automotive industry. The aim of this article is to create this knowledge base. One of the following types of AMR technology can be used to supply assembly lines autonomously: towing vehicles, forklifts, and unit load carriers. The article focuses on the implementation of unit load carriers.

\section{Literature review}

\subsection{AGV classification}

Overall, AGV is a vehicle which can move in predetermined and specific direction automatically without human interference [1]. More specifically, AGV is a device for moving unit loads of materials from one place to another, within a facility, with no accompanying human operator. Vehicles are battery powered and an on-board computer controls the movement [2].

Gul and Rahiman [3] divide AGVs according to a path guidance principle into static and dynamic path vehicles. The static path vehicle uses pre-defined path between its origin and destination point. The dynamic path vehicle behaves autonomously to determine path by detecting and avoiding obstacle. Wang, Tao a Liu [4] states that traditional AGV plans routes by electromagnetic pathfollowing system, and avoids barriers by simple sensors, thus ensuring automatic driving along preset routes. On the contrary, modern AGVs are based on combination of RFID automatic recognition technology, laser guiding technology, wireless communication technology and model feature matching technology. They also state that the efficiency of route planning and group scheduling is increased significantly by combining with big data, the internet of things (IOT) technology and intelligence algorithms.

Gul, Rahiman a Nazli Alhady [5] divide AGVs according to technology of navigation into: (1) wired type, (2) guide type, (3) laser type, (4) gyro based, and (5) vision based. Vision based AGVs that use camera to acquire environment features and made decision based on those features to navigate the vehicle can be considered the highest level of technology.

\subsection{AMRs in industrial logistics}

In this study, AMRs are considered to be a subgroup of AGVs with a high degree of autonomous control by intelligence algorithms, dynamic path system, wireless communication technology, model matching technology, and primarily the vision-based navigation technology. A number of other AMR designations appear in scientific publications: Mobile Autonomous Robots (MAR),
Autonomously Moving Vehicles (AMV), or Mobile Autonomous Units (MAU). The authors consider these names synonymous.

Unger, Markert and Müller [6] state that AMRs are "mobile robots that can perceive their surroundings via various sensors and are able to react to changes in their environment" whereas "mobile robots are a special form of robots that consist of at least the components drive, control and manipulator and are able to move and navigate freely in a given area to fulfil various tasks". At the same time, these authors define the basic characteristics of AMRs: "They are capable of solving tasks with higher complexity without every single process step being explicitly taught. Programming of such devices is in general more task oriented and rule based (higher level of abstraction) than jobs of conventional robots. Solutions to problems are generated by algorithms in real time to cope with variations in processes."

Scientific literature examines the benefits of AMR implementation in logistics systems. Zhang, Hu and Guan [7] define the following benefits: (1) Autonomous path planning, high level of flexibility, (2) The system operates steadily and safely, (3) High degree of intelligence and fewer staff members, and (4) Battery driven, green and environmentally friendly. Similarly, Unger, Markert and Müller [6] state the following benefits: (1) Higher flexibility in processes, (2) Improved ergonomic scorings of close by workstations, (3) Improved degree of capacity utilization for robots, (4) Higher economic efficiency and process stability, and (5) Automation of currently not automatable processes.

\subsection{AMRs for supplying the automotive assembly lines and workplaces}

Several studies dealing with the implementation of AMR technology in the automotive industry were found during the systematic literature review. Several of these studies dealt specifically with the use of AMR technology to supply the assembly line.

In their study, Koo, Yang and Suh [8] addressed the issue of determining the size of the AMR fleet needed for trouble-free operation of given production system. When determining the number of AMRs deployed, they took into account, in particular, the total vehicle travel time that includes empty vehicle travel time, loading time, loaded vehicle travel time, and unloading time. They defined an algorithm to determine the optimal fleet size based on the knowledge of travel time and frequency between locations.

Fathi et al. [9] developed an optimization model for material supply scheduling at missed-model assembly lines. The aim of the study was to optimally schedule the delivery of raw material at assembly lines while using the minimum number of vehicles. This model also provides accurate information on the planned deliveries, material type and quantity in a given cycle and the type of handling technology used. 
Kern, Lämmermann and Bauernhansl [10] proposed an integrated logistics concept for a modular assembly system. They describe a case study of the implementation of the integrated production logistics concept using AMR on the case of a pre-assembly line in a German car manufacturer. The subject of the case study was a preassembly line with manufacturing cells. In designing the concept, they considered consumed parts, logistics area, material flow, assembly sequences, and rules for assigning to workstations. The proposed concept made it possible to reduce the number of buffers, storage areas, handling units and parts inventory.

Zhang, Hu and Guan [7] proposed a hybrid-load AMR dispatching model, which allocates different types of AMR for different sizes of materials, for mixed-model car assembly line. The model is based on a combining the single-load and multi-load dispatching system. They used a genetic algorithm to solve the problem. The criterion of optimization is minimization of the total cost of logistics system.

Kousi et al. [11] designed a service oriented, web-based control system that would enable the monitoring of the shop floor status and the dynamic scheduling of material supply operations in a car assembly system using AMR technology. The control system is based on time and inventory data. Next, Kousi et al. [12] proposed a decisionmaking method for plan generation of part supply operations undertaken by AMR. The results of this study indicated that the method can provide high quality solutions, in terms of production volume and minimization of the line stoppages.

All the above studies proposed optimization models for selected AMR implementation and control problems for supplying automotive assembly lines, especially AMR fleet size determination, material supply planning and scheduling optimization, and selecting the AMR dispatching model. However, no study dealt with the issue comprehensively and in terms of managerial implications. The literature lacks a comprehensive set of recommendations that can serve as a knowledge base for the design, selection and implementation of AMR technology for supplying assembly lines in the automotive industry.

\section{Research methodology}

The basic research tool was a case study aimed at assessing the feasibility of introducing AMR technology for supplying car assembly line with parts with irregular consumption in a leading passenger car manufacturer.

Case study have often been considered as one of the basic methods of qualitative research, although it may also be quantitative or contain a combination of qualitative and quantitative approaches [13]. It is a research method involving an up-close, in-depth, and detailed examination of a subject of study (the case), as well as its related contextual conditions. There are various case study categorizations. For the needs of the presented research explanatory [14], intrinsic [15], and evaluative [16] case study was chosen.

At the beginning of the research, there was the requirement of the car manufacturer to assess replacing the current method of supplying the assembly line using human operated tow trains with vision based AMR supplying system. One of the following types of AMR technology could be used to supply assembly lines autonomously: towing vehicles, forklifts, and unit load carriers. The case study focuses on assessing the implementation of unit load carriers.

The study analysed the current state of supplying of the assembly line. The subject of the analysis was 88 workstations of the assembly line supplied with irregularly consumed parts, because regularly supplied parts are supplied by standard AGVs (with pre-defined paths). The parts are loaded in pallet containers which are placed on rolling racks. The containers and racks represent a handling unit.

The researched process was characterized by a high number of different combinations of supplied workstations, i.e. paths. The frequency of parts deliveries to workstations was on average 46 per hour, at peak times up to 80 per hour. Process of supplying workstations with parts begins with the emergence of need and call-of the parts from a particular workstation by an operator using a button and continues by picking the required parts from the warehouse at train station where the handling units are loaded onto the tow train. The process then continues with parts delivery to each workstation, whereas one tow train usually transports three handling units to three different workstations. Routing is based on the experience of tow train drivers. The full handling unit is unloaded and handled by the driver to a predetermined location at the target workstation. Next, the driver handles and loads an empty handling unit on the tow train. After performing the above operations at all three workstations, the tow train returns to the train station where empty handling units are unloaded on the designated area and the tow train is ready for another mission.

In the case study, research of currently available technologies was carried out and 76 vendors of potentially suitable technologies were identified. Based on a more detailed analysis of the technologies offered, 17 vendors were shortlisted, among whom a tender procedure was carried out. Benchmarking with other plants and external industrial companies was also carried out during the study. However, no case with a larger AMR fleet was found. Based on the information obtained, the proposal of the concept of AMR supplying the assembly line and the proposal of technological solution were carried out in three variants. A capacity calculation indicating the number of required AMRs was performed for each variant. Subsequently, three proposed variants were economically evaluated. 


\section{$4 \quad$ Results and discussion}

Based on the performed research and case study, the general procedure for feasibility study of the project of
AMR assembly line supply can be proposed. The procedure includes eight steps in recommended sequence, while some of the steps can be carried out in parallel as shown in Figure 1.

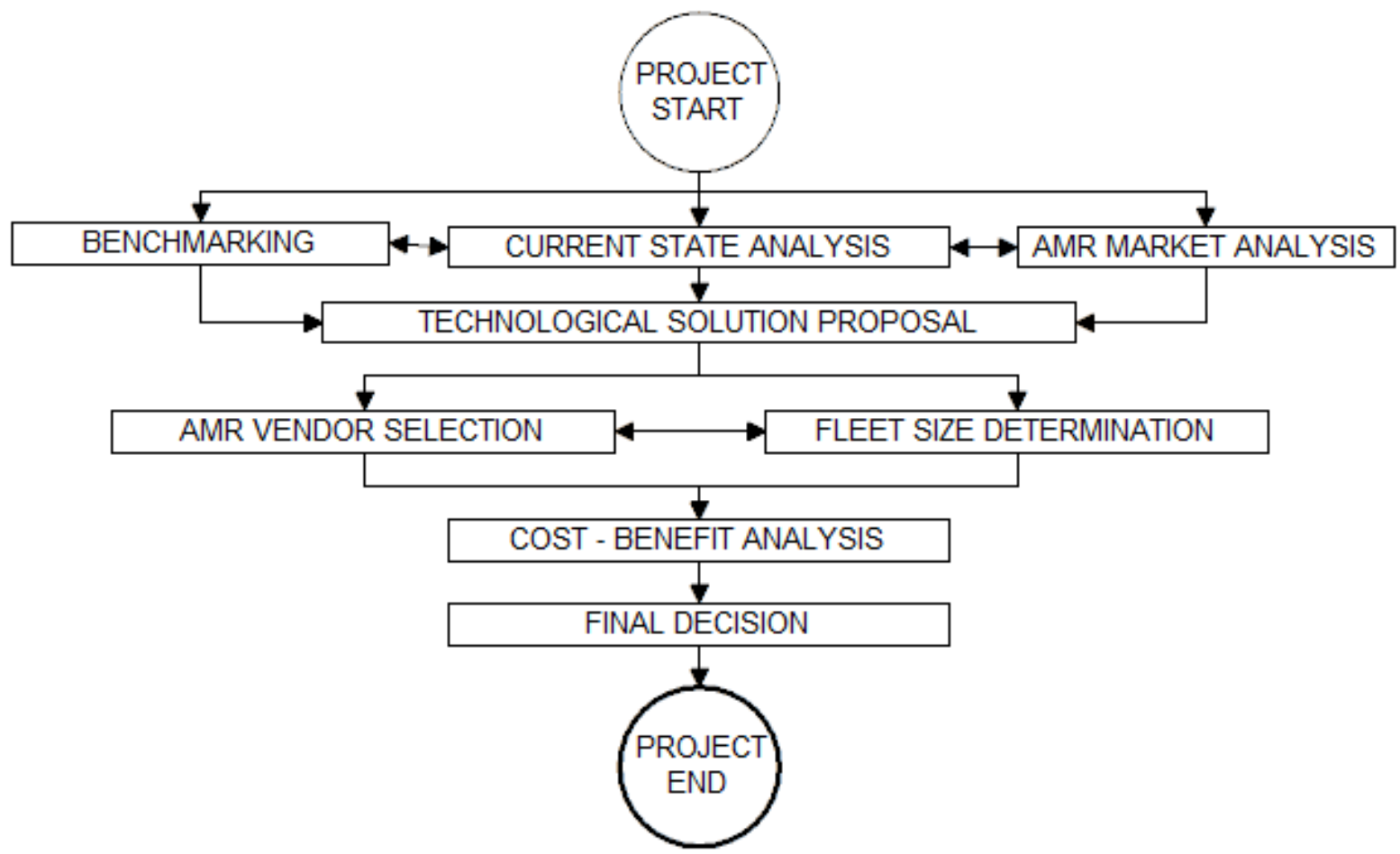

Figure 1 General procedure for feasibility study of the project of AMR assembly line supply

1. Benchmarking - internal and external (competitive and functional) benchmarking of existing implementations.

2. Current state analysis - analysis of supplied workplaces, supplied parts, process of loading and unloading, frequency of supplying, manipulation units and packages, weight of supplied units, principles of supplying.

3. AMR market analysis - search for available vendors and technologies, rough evaluation and selection of suitable vendors and technologies.

4. Technological solution proposal - narrow selection of the most suitable technologies, proposal of supplying concept.

5. AMR vendor selection - requirements specification, contacting suitable vendors, evaluation of business offers, final selection of the most relevant vendors.

6. Fleet size determination - calculation considering the supply needs, capacity, speed, manipulation times and other parameters of selected technology.

7. Cost-benefit analysis - calculation considering initial investments, operation costs, savings and return on investment, comparison of selected technologies and vendors.
8. Final decision - final selection of specific technology and vendor.

The following subchapters present generalized conclusions formulated based on the findings of the case study. The conclusions are structured into five categories and represent a set of recommendations that can serve as a knowledge base for designing, selecting and implementing unit load carriers type of AMR technology for supplying assembly lines in the automotive industry.

\subsection{Technology}

This category focuses on the technical aspects of AMR implementation, particularly in terms of additional technologies and accessories:

- The use of AMR technology to supply assembly lines usually requires their customization by purchasing special top modules (e.g. lift, hook, roller conveyor). Their choice depends on the type of handling operation and unit.

- It is important to decide whether the task of AMR system is only to transport (handling at the station and workstation is carried out by workers) or also to exchange the handling units (full/empty) and place them in a precisely defined location. For autonomous loading and unloading of handling units, it is necessary to select special accessories 
again. For example, racks and docks are commonly used for this purpose. However, their use increases space requirements at the assembly line (setting up an additional exchanging space). It is better to look for solutions that do not require additional space.

- Most AMRs in the basic version are unable to identify the parts being transported. This is important so that the AMR recognizes the target workstation at the train station. For automatic identification of transported parts, it is necessary to equip the AMR with additional technology, e.g. a camera enabling recognition of $\mathrm{QR}$ codes, which will be used to mark the handling units.

- An important criterion for the selection of technology is the range of load-bearing capacity of individual types. Some vendors specialize only in a certain load capacity (e.g. up to $100 \mathrm{~kg}$ or over $1000 \mathrm{~kg}$ ). In order to select the appropriate technology, it is necessary to perform an analysis of the weight of the loaded handling units. Based on it, AMR fleet with appropriate ratios of load capacities should be selected.

- It is necessary to count on the allocation of the AMR charging area, which should be located in the immediate vicinity of the station.

\subsection{Management}

This category is oriented on the managerial and control aspects of AMR implementation:

- The handling operations performed by AMR at the workstations are so time consuming that basically a single-pallet system cannot be used. However, the two-pallet system is the standard in the automotive industry.

- The use of AMR to supply assembly line with irregularly consumed parts requires an advanced fleet management system based on advanced technologies (artificial intelligence) that allow efficient AMR collaboration and the whole fleet control. The importance of using this system grows with the number of AMRs in the fleet.

- In a classic automotive plant, several handling technologies (e.g. human operated or automated guided trains and forklifts), including pedestrians, are combined and they meet on the roads, which should be taken into account when designing the implementation, mainly to maintain road throughput.

- A preferred solution should be to introduce AMR and/or AGV technology from a single vendor. The simultaneous use of technologies from different vendors raises problems resulting from the reluctance of vendors to cooperate. This makes it difficult to implement an integrated control system. Managing technologies and systems from different vendors also increases the administrative and financial resources requirements.

- The implementation of AMR technology enables increased road safety compared to humanoperated tow trains. AMRs are equipped with advanced safety systems and move at a lower speed.

- There is little experience to date with the quality and reliability of AMR systems. The technology has not been proven on a larger scale in the automotive industry. It is therefore necessary to take into account the need to eliminate a relatively large number of errors during the start-up of the technology.

- It is convenient to select a technology that allows the user to manage the entire system. Many systems cannot work without close cooperation with the vendor both during the implementation and the operation phase, which reduces the flexibility of setting up and managing the entire system and also increases the implementation and operation costs.

\subsection{Economics}

This category presents conclusions and insights on the cost of the technology and the return on investment:

- Features and functionality (navigation method, charging time, dimensions, fleet management, ability to bypass an obstacle, solution of crossroads, etc.) of AMRs available on the market is very diverse for a relatively similar price. Thus, the most advanced AMR technologies can be almost as affordable as standard AGV technologies.

- Depending on the chosen type of AMR, additional costs for top modules and accessories (e.g. racks, docks) allowing loading and unloading, identification of handling units, as well as for the modification or purchase of new rolling racks have to be expected.

- The return on investment of AMR technology implementation as a substitute for human operated supply depends mainly on personnel costs. Faster returns can be achieved especially in locations with expensive labour. However, the total elimination of personnel costs cannot be expected, as it will be necessary to establish the position of the AMR fleet dispatcher.

\subsection{Capacity}

This category focuses on the conclusions and findings regarding the calculation of the appropriate number of AMRs, i.e. the fleet size needed to supply the assembly line: 
- AMR moves slower than human-operated tow train. In order to secure the supply of the assembly line, there will be more AMRs in operation, which may overload selected roads and create traffic bottlenecks.

- The fact that the AMR real average speed differs significantly from the maximum speed indicated by the vendors must be taken into account in the capacity calculation. This depends mainly on the nature of the loaded handling units and the road traffic density.

- The calculation of the required number of AMRs is based on the determination of the AMRs total travel and handling time. The total time depends on the assembly line requirements in a specific period. The travel time is a multiple of AMR speed and the total distance travelled by AMRs in the given period. The handling time is a multiple of the time of one handling operation (unloading or loading of one manipulation unit) and the number of handling operations in the given period. Other times, which should be taken into account when determining the required number of AMRs are the charging time and a time reserve for other scheduled or unexpected events (e.g. maintenance, breakdowns, collisions).

- Supplying the irregularly consumed parts will result in peaks in real operation. These peaks cannot be fully covered by increasing number of AMRs. Their number would be so high that there would be a significant decrease in the average AMRs utilization and overall system inefficiency. It is therefore advisable to operate an alternative supply system for the peaks.

\subsection{Vendors}

This category presents the conclusions and findings of the AMR market analysis:

- The generally available public information on AMR technologies and the specifications published by the vendors are problematic, vague and often misleading and cannot lead to a relevant selection. Direct communication with vendors is essential for the initial selection of suitable technologies.

- Vendors come from different countries of the world, but regional support is needed for AMR technology selection, implementation, and operation. Unfortunately, the support is not available for all vendors or can be very problematic if they are located far from the implementation site.

- To date, there are very few applications with a larger fleet of AMRs in the field of assembly manufacturing, which makes it impossible to obtain relevant references and practical experience with a particular technology.

- Many vendors are specialized. They develop tailor-made AMRs for special purposes and do not provide standard ready to use solutions.

\section{Conclusion}

The use of AMR technology for supplying assembly lines in the automotive industry, especially for supplying irregularly consumable parts, represents a great potential for companies' efficiency improvement. However, its implementation is also a major challenge. Although technology and the AMR market are evolving rapidly, there is still a lack of experience in deploying a larger fleet of AMRs. Since its implementation requires relatively large investments, the decision and the subsequent implementation project must be based on a comprehensive and high-quality knowledge base. For this purpose, the article presents a comprehensive set of recommendations that address the technological, managerial and control, economics, capacity and vendors aspects of the design, selection and implementation of AMR technology for supplying assembly lines in the automotive industry. Based on the performed research, it is not possible to unambiguously recommend a specific AMR technology for supplying the assembly line in the automotive industry. When considering the implementation of the AMR fleet, each company should responsibly approach the research and assessment of the suitability of currently available technologies. The criteria for selecting the appropriate technology must always be based on the specific needs and capabilities of a particular company. In addition to the technical and economic parameters of individual technologies, it is necessary to take into account factors concerning, for example, the possibilities of selfgovernment of the entire system, compatibility with technologies operated in parallel or supplier support. An important factor for the design of the assembly line supply system in the automotive system and the selection of a suitable technology is also the capacity calculation, resp. fleet size and traffic load. The issue of the implementation of AMR for supplying the assembly lines in the automotive industry is complex and the assessment of the suitability of a particular technology depends primarily on setting the significance of the individual criteria assessed. In general, given the dynamics of development of this field, it is possible to recommend an orientation to the most advanced technologies and user-friendliness of the entire solution, which plays an important role in real operation.

\section{References}

[1] CHEVALIER, P., POCHET, Y., TALBOTT, L.: Design of a 2-stations automated guided vehicle systems, in: KLOSE A., SPERANZA M.G., Van WASSENHOVE L.N.: Quantitative Approaches to distribution logistics and supply chain management, 
Lecture Notes in Economics and Mathematical Systems, Vol. 519, Springer, Berlin, Heidelberg, Germany, 2002. doi:10.1007/978-3-642-56183-2_18.

[2] BRALLA, J.G.: Handbook of Manufacturing Processes - How Products, Components and Materials are Made, New York, Industrial Press, 2007.

[3] GUL, F., RAHIMAN, W.: An Integrated approach for Path Planning for Mobile Robot Using Bi-RRT, in: IOP Conference Series: Materials Science and Engineering, Vol. 697, pp. 12-22, 2019. doi:10.1088/1757899X/697/1/012022

[4] WANG, T., TAO, Y., LIU, H.: Current Researches and Future Development Trend of Intelligent Robot: A Review, International Journal of Automation and Computing, Vol. 15, No. 5, pp. 525-546, 2018. doi:10.1007/s11633-018-1115-1

[5] GUL, F., RAHIMAN, W., NAZLI ALHADY, S.: A comprehensive study for robot navigation techniques, Cogent Engineering, Vol. 6, No. 1, 2019. doi:10.1080/23311916.2019.1632046

[6] UNGER, H., MARKERT, T., MULlER, E., Evaluation of use cases of autonomous mobile robots in factory environments, Procedia Manufacturing, Vol. 17, pp. 254-261, 2018. doi:10.1016/j.promfg.2018.10.044

[7] ZHANG, L., HU, Y., GUAN, Y.: Research on hybridload AGV dispatching problem for mixed-model automobile assembly line, Procedia CIRP, Vol. 81, pp. 1059-1064, 2019. doi: 10.1016/j.procir.2019.03.251

[8] KOO, P., JANG, J., SUH, J.: Estimation of Part Waiting Time and Fleet Sizing in AGV Systems, International Journal of Flexible Manufacturing Systems, Vol. 16, pp. 211-228, 2004. doi: $10.1007 / \mathrm{s} 10696-005-1008-9$
[9] FATHI, M., SYBERFELDTT, A., GHOBAKHLOO, M., ESKANDARI, H.: An optimization model for material supply scheduling at mixed-model assembly lines, Procedia CIRP, Vol. 72, pp. 1258-1263, 2018.

[10] KERN, W., LAMMERMANNN, H., BAUERHANSL, T.: An Integrated Logistics Concept for a Modular Assembly System, Procedia Manufacturing, Vol. 11, pp. 957-964, 2017. doi:10.1016/j.procir.2018.03.274

[11] KOUSI, N., KOUKAS, S., MICHALOS, G., MAKRIS, S., CHRYSSOLOURIS, G.: Service Oriented Architecture for Dynamic Scheduling of Mobile Robots for Material Supply, Procedia CIRP, Vol. 55, pp. 18-22, 2016. doi:10.1016/j.procir.2016.09.014

[12] KOUSI, N., MICHALOS G., MAKRIS, S., CHRYSSOLOURIS, G.: Short - term Planning for Part Supply in Assembly Lines Using Mobile Robots, Procedia CIRP, Vol. 44, pp. 371-376, 2016. doi:10.1016/j.procir.2016.02.131

[13] STARMAN, A.B.: The case study as a type of qualitative research, Journal of Contemporary Educational Studies/Sodobna Pedagogika, Vol. 64, pp. 28-43, 2013.

[14] YIN, R.K.: Case Study Research: Design and Methods, SAGE: Beverly Hills, California, USA, 1984.

[15] STAKE, R.E.: The Art of Case Study Research, SAGE: London, England, 1995.

[16] McDONOUGH, J., McDONOUGH, S.: Research Methods for English Language Teachers, Arnold: London, England, 1997.

\section{Review process}

Single-blind peer review process. 